Proceedings

\title{
Cytotoxic Effect of Hydroxytyrosol and Its Semisynthetic Derivatives against Prostate Cancer Cells ${ }^{\dagger}$
}

\author{
Antonio J. León-González 1,2,3,4,* , Prudencio Sáez-Martínez 1,2,3,4, Juan M. Jiménez-Vacas ${ }^{1,2,3,4}$, \\ Vicente Herrero-Aguayo 1,2,3,4, Antonio J. Montero-Hidalgo 1,2,3,4, Enrique Gómez-Gómez 1,3,5, \\ Andrés Madrona ${ }^{6}$, Justo P. Castaño 1,2,3,4, José L. Espartero ${ }^{6}$, Manuel D. Gahete 1,2,3,4 and Raúl M. \\ Luque $1,2,3,4, *$ \\ 1 Maimonides Institute of Biomedical Research of Cordoba (IMIBIC), 14004 Cordoba, Spain; \\ prudensama95@gmail.com (P.S.-M.); b12jivaj@uco.es (J.M.J.-V.); b22heagv@uco.es (V.H.-A.); \\ b42mohia@uco.es (A.J.M.-H.); enriquegomezgomez@yahoo.es (E.G.-G.); email6@gmail.com (J.P.C.); \\ email7@gmail.com (M.D.G.) \\ 2 Department of Cell Biology, Physiology and Immunology, University of Cordoba, 14004 Cordoba, Spain \\ 3 Reina Sofia University Hospital (HURS), 14004 Cordoba, Spain \\ 4 CIBER Physiopathology of Obesity and Nutrition (CIBERobn), 14004 Cordoba, Spain \\ 5 Urology Service, HURS/IMIBIC, 14004 Cordoba, Spain \\ 6 Department of Organic and Pharmaceutical Chemistry, University of Seville, 41012 Seville, Spain; \\ email8@gmail.com (A.M.); email9@gmail.com (J.L.E.) \\ 7 Address: Edificio IMIBIC. Av. Menéndez Pidal s/n. 14004 Córdoba, Spain \\ * Correspondence: antonio.leon@imibic.org (A.J.L.-G.); raul.luque@uco.es (R.M.L.); Tel.: +34-957213740 \\ + Presented at the 1st International e-Conference on Antioxidants in Health and Disease, 01-15 December \\ 2020; Available online: https://cahd2020.sciforum.net/.
}

Published: 30 November 2020

\begin{abstract}
Intake of olive oil as the main source of fat in Mediterranean diet is related to positive effects on human health. The olive biophenol hydroxytyrosol (HT) is considered a promising cancer chemopreventive compound against different types of cancer. The aim of the present study was to compare the cytotoxic activity against prostate cancer (PCa) cell lines of HT, obtained from olive mill wastewaters, and five semisynthetic alkyl ether, ester, and nitro-derivatives. HT, hydroxytyrosyl acetate (HT-Ac) and ethyl hydroxytyrosyl ether (HT-Et) exerted higher cytotoxic effect against 22Rv1 and PC-3 PCa cell lines than in non-malignant RWPE-1 cells. These compounds also significantly decreased the migration rate of RWPE-1 and PC-3 cells and the colony and prostatosphere formation of 22Rv1 cells. However, HT-Ac and HT-Et, but not HT, were able to decrease p-AKT levels and colony and prostatosphere formation in PC-3. In sum, our results together with previous studies showing the antioxidant capacity of HT and its lipophilic derivatives suggest that they could be considered as potential therapeutic tools in PCa.
\end{abstract}

Keywords: anticancer; extra virgin olive oil; hydroxytyrosol; hydroxytyrosyl acetate; prostate cancer; semisynthetic derivatives

Dietary fruits and vegetables are the source of a wide variety of compounds with interest in the treatment and prevention of cancer. In this sense, recent studies relate a high adherence to the Mediterranean diet with a lower incidence, aggressiveness and mortality of prostate cancer (PCa) [1- 
The 1st International Electronic Conference on Antioxidants in Health and Disease, 1-15 December 2020

4]. PCa is the second most diagnosed cancer type and the sixth cause of cancer death among men worldwide [5].

Edible fruits and vegetables from Mediterranean diet are the source of bioactive compounds with interest in the treatment and prevention of PCa [3]. Particularly, there is growing interest in the role of bioactive compounds of extra virgin olive oil (EVOO) in different types of cancer, including PCa [6]. Among them, phenolic alcohols [i.e., tyrosol, hydroxytyrosol (HT)] and their derivatives (i.e., oleocanthal and other secoiridoids) exerted promising anticancer effects in previous in vivo preclinical models of other types of cancer, and have been shown to reduce PCa cell proliferation in vitro [7]. In addition, it has been reported that HT and their derivatives induce apoptosis and lead to cell cycle arrest in different PCa cell lines by suppressing multiple signaling pathways [8].

The olive mill waste waters are a by-product of olive oil industry, which were considered earlier as a great environmental problem, but are nowadays appreciated as an excellent source of HT and other biophenols with interest in agri-food, cosmetic and pharmaceutical industries [9]. Moreover, during the last years, new chemical derivatives of HT have been developed. Previous studies of our group reported the synthesis of ester and ether derivatives of HT and nitro-HT and revealed that some of these modifications could improve the absorption and pharmacological activities of HT, including antioxidant, anti-inflammatory, antiplatelet, neuroprotective, anti-angiogenic and anticancer effects [10-14]. However, the effects of these HT derivatives in PCa are still poorly studied.

This background led us to study the chemopreventive effect against PCa of HT, one of the main bioactive phytochemicals of olive oil obtained from olive mill wastewaters, and five semisynthetic derivatives obtained by introduction of ether, acetate, and/or nitro groups (Figure 1). These derivatives showed higher antioxidant capacity than HT in previous studies and their increased lipophilicity improved their physic-chemical properties to be included in formulations of functional foods. We hypothesized that these derivatives could also improve the PCa chemopreventive effect of HT, as occurred in other pathologies. Therefore, the aim of this study was to determine and compare the in vitro anticancer effect and mechanism of actions of HT and its semisynthetic derivatives, in both non-malignant (RWPE-1) and cancerous (22Rv1 and PC-3) prostate cell lines. This study would enable the evaluation of HT and its derivatives as potential novel phytochemicals in PCa chemoprevention, which could be used as part of functional foods or in the formulation of enriched EVOO.

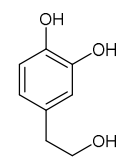

HT

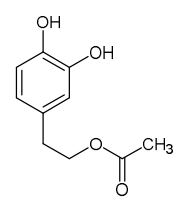

HT-AC

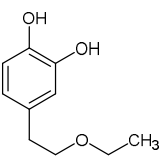

HT-Et

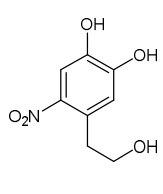

$\mathrm{NO}_{2} \mathrm{HT}$

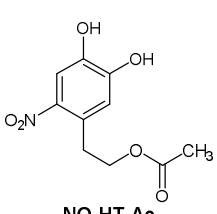

$\mathrm{NO}_{2} \mathrm{HT}-\mathrm{Ac}$

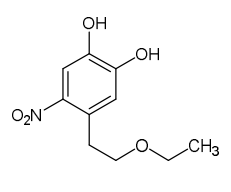

$\mathrm{NO}_{2} \mathrm{HT}-\mathrm{Et}$

Figure 1. Chemical structures of the tested compounds. Hydroxytyrosol (HT) and derivatives: hydroxytyrosyl acetate (HT-Ac), ethyl hydroxytyrosyl ether (HT-Et), nitrohydroxytyrosol $\left(\mathrm{NO}_{2} \mathrm{HT}\right)$, nitrohydroxytyrosyl acetate ( $\left.\mathrm{NO}_{2} \mathrm{HT}-\mathrm{Ac}\right)$, and ethyl nitrohydroxytyrosyl ether ( $\left.\mathrm{NO}_{2} \mathrm{HT}-\mathrm{Et}\right)$.

\section{Results and Discussion}

\subsection{Hydroxytyrosol and Five Semisynthetic Derivatives Exert a Concentration-Dependent Effect in Proliferation of Prostate Cells}

To compare the antiproliferative effect of five HT derivatives with the parent compound, the proliferation rate of the non-tumor prostate epithelial cell line, RWPE-1, and the tumor cell line PC-3 was measured after $48 \mathrm{~h}$ of incubation with these compounds $(0,10,30,100$ and $300 \mu \mathrm{M})$. Specifically, the proliferation capacity of both cell lines decreased after treatment with all the tested compounds in a range of concentrations of 30 to $300 \mu \mathrm{M}$ (Figure 2). 


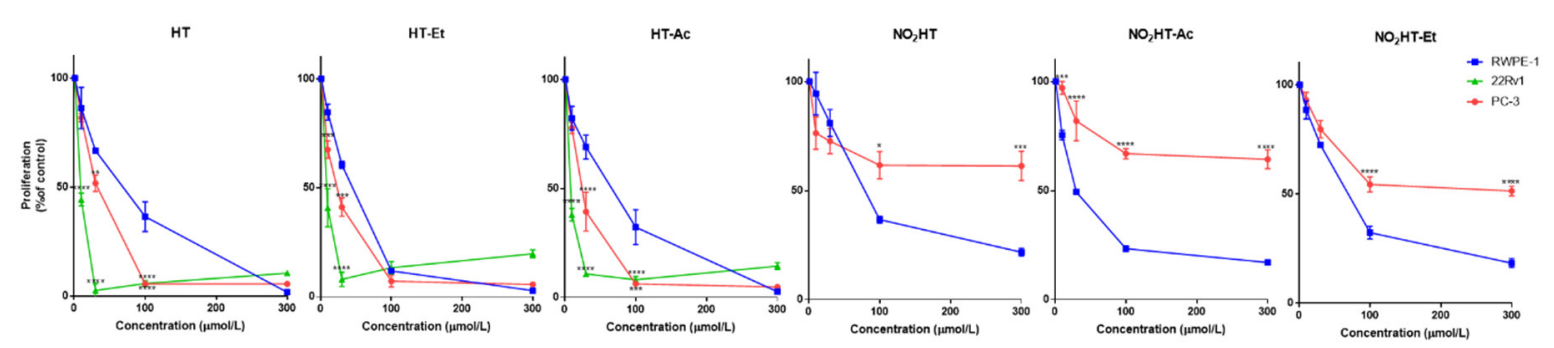

Figure 2. Concentration-response curves on cell proliferation of HT and derivatives ( $48 \mathrm{~h}$ treatment) in RWPE-1 (squares), 22Rv1 (triangles) and PC-3 (circles). Data are expressed as percent of control proliferation (set at $100 \%$ ) and represent the mean \pm SEM (4 experiments) vs. the logarithm of each compound concentration $(\mu \mathrm{M})$. Asterisks indicate statistically significant differences with RWPE-1: * $p<0.05,{ }^{* *} p<0.01,{ }^{* * *} p<0.001,{ }^{* * * *} p<0.0001$.

Native HT and two of its derivatives, HT-Ac and HT-Et, had a selective antiproliferative effect against cancer cells, as it was significantly higher in tumor PC-3 cells rather than in RWPE-1 at specific concentrations (HT exerted a selective effect at $100 \mu \mathrm{M}$, whereas HT-Ac was selective at 30 and 100 $\mu \mathrm{M}$ and HT-Et was at 10 and $30 \mu \mathrm{M}$ ). This result agrees with previous studies, where HT and alkyl ether derivatives, including HT-Et induced a higher cytotoxic effect in lung or prostate cancer cells than in the corresponding normal cells $[8,14]$.

In contrast, the nitro-derivatives were more cytotoxic in the non-malignant cells. This result indicates that the introduction of a nitro group reduces the selective anticancer effect of HT. Moreover, as shown by López-Jiménez et al., the nitro-containing HT derivatives were much weaker antiangiogenic compounds, whereas HT-Ac and HT-Et exerted a greater inhibition of the formation of tubule-like structures by endothelial cells in Matrigel [11]. Consequently, HT, HT-Ac and HT-Et, but not the nitro-derivatives, were selected for further experiments in the present study.

To corroborate the antiproliferative activity of the selected compounds in PCa, they were also tested in the 22Rv1 PCa cell line. As occurred in PC-3, an antiproliferative effect of these compounds was also observed in 22Rv1 (Figure 2). The half inhibitory concentrations (IC50, $\mu \mathrm{M}$ ) of the selected compounds in the three cell lines are presented in Table 1. Specifically, the three compounds exerted a selective antiproliferative effect in 22Rv1 at the low micromolar range, although the derivatives showed slightly lower IC50 values in both PC-3 and 22Rv1 cell lines.

Table 1. Half inhibitory concentrations ( $\mathrm{IC}_{50}$ ) of proliferation rates of RWPE-1, PC-3 and 22Rv1 cell lines after $48 \mathrm{~h}$ of treatment with HT and selected derivatives. Data are expressed as the mean of IC 50 $(\mu \mathrm{M}) \pm$ SEM (4 experiments).

\begin{tabular}{lcll}
\hline Compound & RWPE-1 & \multicolumn{1}{c}{ PC-3 } & \multicolumn{1}{c}{ 22Rv1 } \\
\hline \multirow{2}{*}{ HT } & \multirow{2}{*}{$52.20 \pm 4.19$} & $\begin{array}{l}28.88 \pm 2.25^{* *} \\
(p, 0.0032)\end{array}$ & $\begin{array}{l}9.32 \pm 0.50^{* * *} \\
(p<0.0001)\end{array}$ \\
& & $\begin{array}{l}23.40 \pm 3.20^{* * *} \\
7\end{array}$ & $\begin{array}{l}7.65 \pm 0.50^{* *} \\
(p, 0.0002)\end{array}$ \\
HT-Ac & \multirow{2}{*}{$54.18 \pm 11.70 .0001)$} \\
& & $\begin{array}{l}20.30 \pm 3.09 \\
(p, 0.0691)\end{array}$ & $\begin{array}{l}9.18 \pm 1.48^{* *} \\
(p, 0.0011)\end{array}$ \\
\hline
\end{tabular}

Asterisks indicate significant differences to the respective RWPE-1 value: ${ }^{* *} p<0.01,{ }^{* * *} p<0.001$.

\subsection{HT, HT-Ac, and HT-Et Decrease Migration Capacity of Prostate Cells in a Concentration-Dependent Manner}

To further compare the effect of $\mathrm{HT}$ and the selected derivatives against PCa, the migration of RWPE- 1 and PC-3 cells was assessed after incubation with $0-100 \mu \mathrm{M}$ of these compounds. Treatment with HT, HT-Ac, and HT-Et significantly reduced the migration rate of RWPE-1 and PC-3 cells in a 
The 1st International Electronic Conference on Antioxidants in Health and Disease, 1-15 December 2020

concentration-dependent manner (Figure 3). To the best of our knowledge, this is the first report showing the inhibition of migration capacity in PCa cells mediated by HT derivatives. However, it has been described that different olive biophenols, including HT and oleuropein, inhibit migration and invasion of other cancer cell types, such as triple-negative breast cancer MDA-MB-231 cells [15].
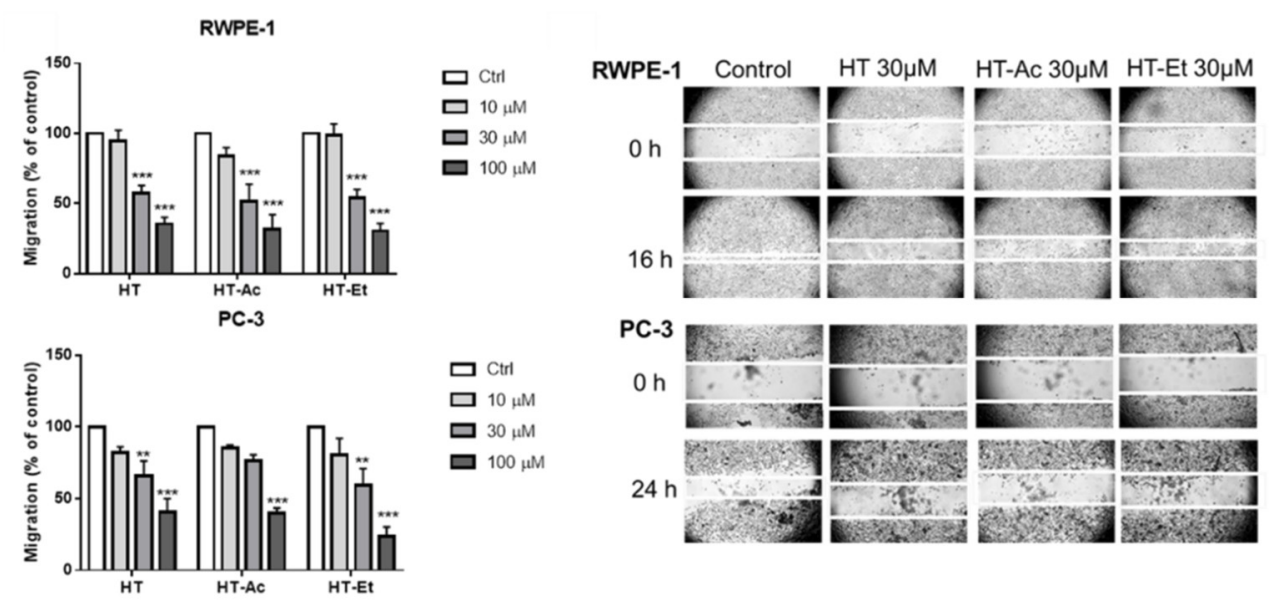

Figure 3. Cell migration rate of RWPE-1 (16 h), and PC-3 (24 h) treated with 0-100 $\mu$ M of HT, HT-Ac, and HT-Et. Data are expressed as migration (percent of control, set at $100 \%$ ) and represent the mean \pm SEM (4 experiments). Asterisks indicate significant differences to the respective control (Ctrl) value: ${ }^{* *} p<0.01,{ }^{* * *} p<0.001$.

\subsection{Effect of HT, HT-Ac, and HT-Et in Cancer Stemness of Prostate Cancer Cells}

Prostate cancer stem cells play a key role in the initiation of PCa and the development of metastasis [16]. The functional effect of the treatment with $20 \mu \mathrm{M}$ of the selected compounds was studied by prostatosphere and clonogenic assays (Figure 4). This concentration was selected in accordance with $\mathrm{IC}_{50}$ values obtained in proliferation assay and is similar to plasma concentrations of HT observed in volunteers after ingestion of EVOO [17].
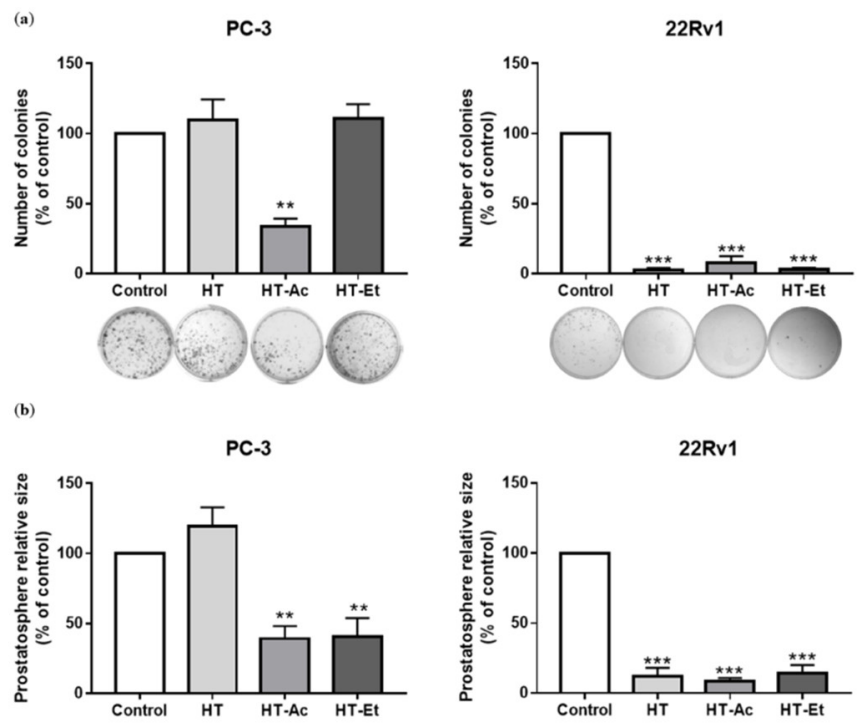

Figure 4. (a) Effect of HT, HT-Ac, and HT-Et treatment ( $20 \mu \mathrm{M}, 10$ days) in the clonogenic assay in PC-3 and 22Rv1 cells. Data are expressed as number of colonies (percent of control, set at 100\%) and 
The 1st International Electronic Conference on Antioxidants in Health and Disease, 1-15 December 2020

represent the mean \pm SEM (4 experiments). Asterisks indicate significant differences compared to the control value: ${ }^{* *} p<0.01,{ }^{* * *} p<0.001$.Effect of HT, HT-Ac, and HT-Et treatment $(20 \mu \mathrm{M}, 14$ days) in the size of PC-3 and 22Rv1 prostatospheres. Data represent the mean area \pm SEM (4 experiments). Asterisks indicate significant differences to the control value: ${ }^{* *} p<0.01,{ }^{* * *} p<0.001$; (b) Effect of HT, HT-Ac, and HT-Et treatment ( $20 \mu \mathrm{M}, 14$ days) in the size of PC-3 and 22Rv1 prostatospheres. Data represent the mean area \pm SEM (4 experiments). Asterisks indicate significant differences to the control value: ${ }^{* *} p<0.01,{ }^{* * *} p<0.001$.

Treatment with each of the three compounds significantly reduced the prostatosphere size and the number of colonies in 22Rv1 cells. According to Cruz-Lozano et al., this effect could be mediated by a reduction of epithelial to mesenchymal transition (EMT) related markers and the Wnt/ $\beta$-catenin signaling pathway, as they observed a decrease of the number of tumorspheres by breast cancer stem cells after treatment with HT accompanied by a modulation of these pathways [18].

In PC-3 cells, HT-Ac and HT-Et, but not HT, reduced the prostatosphere size, while only treatment with HT-Ac significantly diminished the formation of cell colonies, lowering the number of colonies to a $40 \%$ of control. These results suggest that HT derivatives, specially HT-Ac, could improve the anticancer effect of HT against cancer stemness of certain PCa cells that, as PC-3, are deleted in PTEN, a tumor suppressor gene. In fact, PTEN loss has been related with an increase of cancer stem-like populations in PCa [16,19], which, in turns, has been correlated with the activation of Wnt/ $\beta$-catenin activation [20].

\subsection{HT-Ac and HT-Et, but Not HT, Reduce the Activation of AKT in PC-3 Cells}

Aberrant activation of PI3K/AKT and MEK/ERK pathways is related with initiation and progression of different types of cancer, including PCa [21]. The effect in AKT and ERK activation was assessed by Western blot of the proteins extracted from PC-3 and 22Rv1 cells treated with $20 \mu \mathrm{M}$ of the selected compounds for $24 \mathrm{~h}$. HT-Ac and HT-Et, but not HT, were able to downregulate the phosphorylation of AKT at the selected concentration in PC-3, but not 22Rv1, cells (Figure 5).
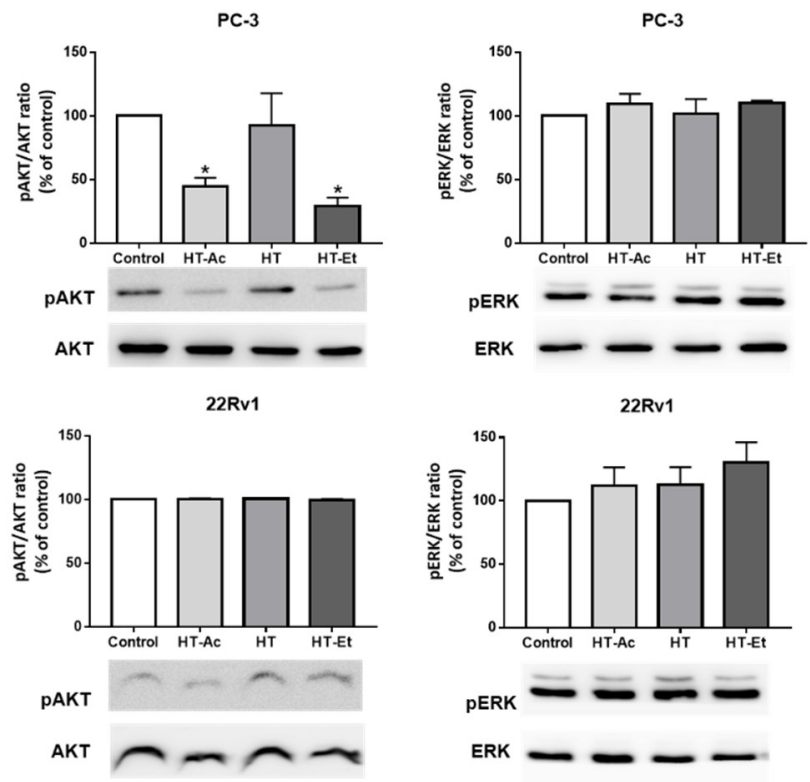

Figure 5. Effect of HT-Ac, HT, and HT-Et treatment $(20 \mu \mathrm{M}, 24 \mathrm{~h})$ in the phosphorylation of AKT and ERK in PC-3 and 22Rv1 cells. Data are calculated as the ratio between pAKT/AKT and pERK/ERK levels, respectively (expressed as percent of control, set at 100\%) and represent the mean \pm SEM (4 experiments). Asterisks indicate significant differences compared to the control value: ${ }^{*} p<0.05$. 
The 1st International Electronic Conference on Antioxidants in Health and Disease, 1-15 December 2020

As previously mentioned, PC-3 cells are deficient in PTEN, which has been related with elevated levels of p-AKT. We have observed that the reduction of the activation of AKT after HT-Ac and HTEt was accompanied by the reduction of the prostatosphere size. This is in accordance with previous studies showing that AKT inhibition was able to avoid the stem cell-like properties of DU145 and 22Rv1 PCa cells depleted in PTEN, such as prostatosphere formation and CD44 $4^{+} / \mathrm{CD}_{133}{ }^{+}$and ALDHpositive cell populations [19]. These results suggest that the derivatives improve the anticancer effect of HT against PC-3 cells at the studied concentration, avoiding the cancer stemness of PC-3 cells by downregulation of the PI3K/AKT pathway. In contrast, no effect was observed in the phosphorylation of ERK in PC-3 cells nor in the activation of AKT and ERK in 22Rv1 cells with any of the compounds at the studied concentration, pointing that these pathways are not altered after treatments with HT, HT-Ac and HT-Et.

\section{Experimental Section}

\subsection{Chemicals}

Olive oil wastewaters were supplied by "Oleícola El Tejar" oil extraction factory in Córdoba, Spain. HT was extracted and purified by column chromatography (95\% purity) as previously described [9]. The five selected HT derivatives, namely hydroxytyrosyl acetate (HT-Ac), ethyl hydroxytyrosyl ether (HT-Et), nitrohydroxytyrosol $\left(\mathrm{NO}_{2} \mathrm{HT}\right)$, nitrohydroxytyrosyl acetate $\left(\mathrm{NO}_{2} \mathrm{HT}-\right.$ $\mathrm{Ac})$, and ethyl nitrohydroxytyrosyl ether ( $\left.\mathrm{NO}_{2} \mathrm{HT}-\mathrm{Et}\right)$, were synthesized as described elsewhere $[12,13,22-24]$. Chemical structures are showed in Figure 1. Stock solutions were prepared by dissolving compounds in DMSO, being its final concentration $<0.1 \%(v / v)$. DMSO dissolved in culture medium was used as control vehicle.

\subsection{Cell Culture}

Cell lines derived from normal prostate (RWPE-1) and PCa (22Rv1 and PC-3) were obtained from the American Type Culture Collection (Manassas, VA, USA) and cultured in a humidified incubator with $5 \% \mathrm{CO}_{2}$ at $37^{\circ} \mathrm{C}$ according to manufacturer instructions, as previously described [2527]. An analysis of short tandem repeats sequences (STRs) was performed to validate these cell lines by using GenePrint 10 System (Promega, Barcelona, Spain), and the absence of mycoplasma was confirmed by PCR as previously reported [28].

\subsection{Cell Proliferation}

Cell proliferation was assessed by resazurin reagent (Canvax Biotech, Cordoba, Spain) as previously reported [25,28]. Briefly, 3000 to 5000 cells were seeded per well in 96-well plates, serumstarved overnight and then exposed to different concentrations (0-300 $\mu \mathrm{M})$ of compounds for $48 \mathrm{~h}$. Cell proliferation was assessed before and after $48 \mathrm{~h}$ of treatment by measuring the fluorescence (560 $\mathrm{nm}$ excitation and $590 \mathrm{~nm}$ emission) after $3 \mathrm{~h}$ incubation with $10 \%$ resazurin by using a FlexStation III system (Molecular Devices, Sunnyvale, CA, USA). Results were expressed as percentage of proliferation referred to control (vehicle-treated). At least three experiments with four replicates of each condition were performed. Paclitaxel, a cytotoxic taxane commonly used in PCa chemotherapy, was used as internal positive control.

\subsection{Cell Migration Assay}

Cell migration was evaluated by wound healing assay as previously described [28,29]. Briefly, 50,000 cells were seeded in 96-well plates and grown until confluence. Wounds were made with IncuCyte WoundMaker (Essen BioScience, Ann Arbor, MI, USA) according to manufacturer's instructions. Wells were then washed with PBS and cells were treated overnight with 0-100 $\mu \mathrm{M}$ of HT or derivatives in serum free medium. Images of the scratch were taken just after wounding $(0 \mathrm{~h})$ and at the end of the treatment. Wound healing was calculated as the ratio between the scratch areas 
The 1st International Electronic Conference on Antioxidants in Health and Disease, 1-15 December 2020

at these two timepoints, measured with ImageJ software. Results were expressed as percentage of migration rate referred to control. At least three experiments with three replicates of each condition were performed. This experiment was performed with RWPE-1 and PC-3 cell lines, but not with 22Rv1 cells, due to their inability to migrate.

\subsection{Clonogenic Assay}

To assess the clonogenic capacity of PC-3 and 22Rv1 PCa cells, 2000 cells were seeded into 6well plates, treated with 0 or $20 \mu \mathrm{M}$ of HT or its derivatives and incubated for 10 days. The medium was then removed, and the colonies were washed with PBS and stained with crystal violet for 30 min, rinsed and air-dried. At least three experiments with two replicates of each condition were performed. Results were expressed as percentage of number of colonies referred to control.

\subsection{Prostatosphere Formation}

Prostatosphere formation assay was carried out in representative cell models of advanced PCa (22Rv1 and PC-3), as previously reported [26,30]. Briefly, 2000 cells/well were seeded in Corning Costar 24-well ultra-low attachment plates (Merck, Madrid, Spain) with DMEM F-12 medium supplemented with $20 \mathrm{ng} / \mathrm{mL}$ EGF (Sigma-Aldrich, Madrid, Spain). Treatments were added while plating the cells and refreshed every 3 days. The area of prostatospheres was determined after 14 days of incubation with ImageJ software. At least three experiments with two replicates of each condition were performed. Results were expressed as percentage of prostatosphere area referred to control.

\subsection{Western Blot Analysis}

Proteins from whole cell lysates were extracted, separated on $10 \%$ SDS-polyacrylamide gels and transferred onto nitrocellulose membranes as previously described [28,29]. Membranes were then probed overnight at $4{ }^{\circ} \mathrm{C}$ with an appropriate primary antibody anti-phospho-AKT, phospho-ERK, AKT or ERK (Cell-Signaling Technology, Danvers, MA, USA). Membranes were thereafter incubated for $1 \mathrm{~h}$ with the corresponding horseradish peroxidase-linked secondary antibody (HRP-conjugated goat anti-rabbit IgG, Cell-Signaling). Immunoreactive bands were detected using ECL chemiluminescence substrate solution (GE Healthcare Europe GmbH, Madrid, Spain) in an enhanced chemiluminescence detection system (GE Healthcare, Madrid, Spain). Observed bands were quantified by using ImageJ software and results were expressed as percentage of control.

\subsection{Statistical Analysis}

All the experiments were performed in at least 3 independent experiments $(n \geq 3)$. The half inhibitory concentration ( $\mathrm{IC}_{50}$ ) values were calculated using the nonlinear regression analysis of cell proliferation. Statistical differences between two variables were calculated by unpaired parametric $\mathrm{t}$ test and nonparametric Mann Whitney U test, according to normality, assessed by KolmogorovSmirnov test. For differences among three variables, One-Way ANOVA analysis was performed. Statistical significance was considered when $p<0.05$. All the analyses were assessed using GraphPad Prism 8 (GraphPad Software, La Jolla, CA, USA).

\section{Conclusions}

Altogether, our data demonstrate that the lipophilic derivatives HT-Ac and HT-Et, not only maintained the anticancer effect of the parent compound HT against PC-3 PCa cells, but also improved its anticancer effect at selected concentrations, as previously hypothesized. These results, together with earlier studies showing increase in the antioxidant and antiangiogenic capacity of HTAc and HT-Et, suggest that these derivatives could be considered as novel therapeutic tools in PCa. 
The 1st International Electronic Conference on Antioxidants in Health and Disease, 1-15 December 2020

Author Contributions: Conceptualization, A.J.L.-G., J.L.E., M.D.G. and R.M.L.; methodology, A.J.L.-G., P.S.-M., J.M.J.-V., V.H.-A., A.J.M.-H., E.G.-G., and A.M.; formal analysis, A.J.L.-G., J.L.E., J.P.C., M.D.G. and R.M.L.; investigation, A.J.L.-G., P.S.-M., J.M.J.-V., V.H.-A., A.J.M.-H., E.G.-G., and A.M.; resources, A.J.L.-G., J.L.E., J.P.C., M.D.G. and R.M.L.; writing - original draft preparation, A.J.L.-G., P.S.-M.; writing - review and editing, A.J.L.G., P.S.-M., J.M.J.-V., V.H.-A., A.J.M.-H., E.G.-G., A.M., J.L.E., J.P.C., M.D.G. and R.M.L.; supervision, A.J.L.-G., J.L.E., J.P.C., M.D.G. and R.M.L.; funding acquisition, A.J.L.-G., J.L.E., J.P.C., M.D.G. and R.M.L. All authors have read and agreed to the published version of the manuscript.

Funding: This research was funded by Junta de Andalucía (PI-0152-2019, BIO-0139), University of Córdoba (Programa Operativo FEDER Andalucía: 27416), Instituto de Salud Carlos III, co-funded by European Union (ERDF/ESF, “Investing in your future”) [PI16/00264, PI17/02287, CD16/00092], MINECO/MECD (BFU201680360-R, FPU17/00263, FPU16/06190, FPU18/02485), and CIBERobn. CIBER is an initiative of Instituto de Salud Carlos III, Ministerio de Sanidad, Servicios Sociales e Igualdad, Spain.

Conflicts of Interest: The authors declare no conflict of interest. The funders had no role in the design of the study; in the collection, analyses, or interpretation of data; in the writing of the manuscript, or in the decision to publish the results.

\section{Abbreviations}

The following abbreviations are used in this manuscript:

$\begin{array}{ll}\text { EVOO } & \text { extra virgin olive oil } \\ \mathrm{HT} & \text { hydroxytyrosol } \\ \mathrm{HT}-\mathrm{Ac} & \text { hydroxytyrosyl acetate } \\ \mathrm{HT}-\mathrm{Et} & \text { ethyl hydroxytyrosyl ether } \\ \text { IC50 } & \text { half inhibitory concentration } \\ \mathrm{NO}_{2} \mathrm{HT} & \text { nitrohydroxytyrosol } \\ \mathrm{NO}_{2} \mathrm{HT}-\mathrm{Ac} & \text { nitrohydroxytyrosyl acetate } \\ \mathrm{NO}_{2} \mathrm{HT}-\mathrm{Et} & \text { ethyl nitrohydroxytyrosyl ether } \\ \text { STRs } & \text { short tandem repeats sequences }\end{array}$

\section{References}

1. Serra-Majem, L.; Roman-Vinas, B.; Sanchez-Villegas, A.; Guasch-Ferre, M.; Corella, D.; La Vecchia, C. Benefits of the Mediterranean diet: Epidemiological and molecular aspects. Mol. Asp. Med. 2019, 67, 1-55, doi:10.1016/j.mam.2019.06.001.

2. Castelló, A.; Boldo, E.; Amiano, P.; Castaño-Vinyals, G.; Aragonés, N.; Gómez-Acebo, I.; Peiró, R.; JimenezMoleón, J.J.J.J.; Alguacil, J.; Tardón, A.; et al. Mediterranean Dietary Pattern is Associated with Low Risk of Aggressive Prostate Cancer: MCC-Spain Study. J. Urol. 2018, 199, 430-437, doi:10.1016/j.juro.2017.08.087.

3. Lopez-Guarnido, O.; Urquiza-Salvat, N.; Saiz, M.; Lozano-Paniagua, D.; Rodrigo, L.; Pascual-Geler, M.; Lorente, J.A.; Alvarez-Cubero, M.J.; Rivas, A. Bioactive compounds of the Mediterranean diet and prostate cancer. Aging Male 2018, 21, 251-260, doi:10.1080/13685538.2018.1430129.

4. Capurso, C.; Vendemiale, G. The Mediterranean Diet Reduces the Risk and Mortality of the Prostate Cancer: A Narrative Review. Front. Nutr. 2017, 4, 38, doi:10.3389/fnut.2017.00038.

5. Culp, M.B.; Soerjomataram, I.; Efstathiou, J.A.; Bray, F.; Jemal, A. Recent Global Patterns in Prostate Cancer Incidence and Mortality Rates. Eur. Urol. 2019, doi:10.1016/j.eururo.2019.08.005.

6. Celano, M.; Maggisano, V.; Lepore, S.M.; Russo, D.; Bulotta, S. Secoiridoids of olive and derivatives as potential coadjuvant drugs in cancer: A critical analysis of experimental studies. Pharmacol. Res. 2019, 142, 77-86, doi:10.1016/j.phrs.2019.01.045.

7. Fabiani, R. Anti-cancer properties of olive oil secoiridoid phenols: A systematic review of: In vivo studies. Food Funct. 2016, 7, 4145-4159.

8. Zubair, H.; Bhardwaj, A.; Ahmad, A.; Srivastava, S.K.; Khan, M.A.; Patel, G.K.; Singh, S.; Singh, A.P. Hydroxytyrosol Induces Apoptosis and Cell Cycle Arrest and Suppresses Multiple Oncogenic Signaling Pathways in Prostate Cancer Cells. Nutr. Cancer 2017, 69, 932-942, doi:10.1080/01635581.2017.1339818. 
The 1st International Electronic Conference on Antioxidants in Health and Disease, 1-15 December 2020

9. Fernandez-Bolanos, J.; Rodriguez, G.; Rodriguez, R.; Heredia, A.; Guillen, R.; Jimenez, A. Production in large quantities of highly purified hydroxytyrosol from liquid-solid waste of two-phase olive oil processing or "Alperujo". J. Agric. Food Chem. 2002, 50, 6804-6811, doi:10.1021/jf011712r.

10. Pereira-Caro, G.; Sarriá, B.; Madrona, A.; Espartero, J.L.; Goya, L.; Bravo, L.; Mateos, R. Alkyl hydroxytyrosyl ethers show protective effects against oxidative stress in HepG2 cells. J. Agric. Food Chem. 2011, 59, 5964-5976, doi:10.1021/jf2002415.

11. Lopez-Jimenez, A.; Gallardo, E.; Espartero, J.L.; Madrona, A.; Quesada, A.R.; Medina, M.A. Comparison of the anti-angiogenic potential of hydroxytyrosol and five derivatives. Food Funct. 2018, 9, 4310-4316, doi:10.1039/c8fo01140k.

12. Gallardo, E.; Palma-Valdes, R.; Sarria, B.; Gallardo, I.; de la Cruz, J.P.; Bravo, L.; Mateos, R.; Espartero, J.L. Synthesis and Antioxidant Activity of Alkyl Nitroderivatives of Hydroxytyrosol. Molecules 2016, 21, 656, doi:10.3390/molecules21050656.

13. Tabernero, M.; Sarria, B.; Largo, C.; Martinez-Lopez, S.; Madrona, A.; Espartero, J.L.; Bravo, L.; Mateos, R. Comparative evaluation of the metabolic effects of hydroxytyrosol and its lipophilic derivatives (hydroxytyrosyl acetate and ethyl hydroxytyrosyl ether) in hypercholesterolemic rats. Food Funct. 2014, 5, 1556-1563, doi:10.1039/c3fo60677e.

14. Calderon-Montano, J.M.; Madrona, A.; Burgos-Moron, E.; Orta, M.L.; Mateos, S.; Espartero, J.L.; LopezLazaro, M. Selective cytotoxic activity of new lipophilic hydroxytyrosol alkyl ether derivatives. J. Agric. Food Chem. 2013, 61, 5046-5053, doi:10.1021/jf400796p.

15. Lu, H.Y.; Zhu, J.S.; Zhang, Z.; Shen, W.J.; Jiang, S.; Long, Y.F.; Wu, B.; Ding, T.; Huan, F.; Wang, S.L. Hydroxytyrosol and Oleuropein Inhibit Migration and Invasion of MDA-MB-231 Triple-Negative Breast Cancer Cell via Induction of Autophagy. Anticancer Agents Med. Chem. 2019, doi:10.2174/1871520619666190722101207.

16. Mei, W.; Lin, X.; Kapoor, A.; Gu, Y.; Zhao, K.; Tang, D. The Contributions of Prostate Cancer Stem Cells in Prostate Cancer Initiation and Metastasis. Cancers 2019, 11, 434, doi:10.3390/cancers11040434.

17. Covas, M.I.; de la Torre, K.; Farre-Albaladejo, M.; Kaikkonen, J.; Fito, M.; Lopez-Sabater, C.; PujadasBastardes, M.A.; Joglar, J.; Weinbrenner, T.; Lamuela-Raventos, R.M.; et al. Postprandial LDL phenolic content and LDL oxidation are modulated by olive oil phenolic compounds in humans. Free Radic Biol. Med. 2006, 40, 608-616, doi:10.1016/j.freeradbiomed.2005.09.027.

18. Cruz-Lozano, M.; Gonzalez-Gonzalez, A.; Marchal, J.A.; Munoz-Muela, E.; Molina, M.P.; Cara, F.E.; Brown, A.M.; Garcia-Rivas, G.; Hernandez-Brenes, C.; Lorente, J.A.; et al. Hydroxytyrosol inhibits cancer stem cells and the metastatic capacity of triple-negative breast cancer cell lines by the simultaneous targeting of epithelial-to-mesenchymal transition, Wnt/beta-catenin and TGFbeta signaling pathways. Eur. J. Nutr. 2019, 58, 3207-3219, doi:10.1007/s00394-018-1864-1.

19. Kim, R.J.; Bae, E.; Hong, Y.K.; Hong, J.Y.; Kim, N.K.; Ahn, H.J.; Oh, J.J.; Park, D.S. PTEN loss-mediated Akt activation increases the properties of cancer stem-like cell populations in prostate cancer. Oncology 2014, 87, 270-279, doi:10.1159/000363186.

20. Francis, J.C.; Thomsen, M.K.; Taketo, M.M.; Swain, A. $\beta$-Catenin Is Required for Prostate Development and Cooperates with Pten Loss to Drive Invasive Carcinoma. PLoS Genet. 2013, 9, e1003180, doi:10.1371/journal.pgen.1003180.

21. Georgi, B.; Korzeniewski, N.; Hadaschik, B.; Grullich, C.; Roth, W.; Sultmann, H.; Pahernik, S.; Hohenfellner, M.; Duensing, S. Evolving therapeutic concepts in prostate cancer based on genome-wide analyses (review). Int. J. Oncol. 2014, 45, 1337-1344, doi:10.3892/ijo.2014.2567.

22. Madrona, A.; Pereira-Caro, G.; Mateos, R.; Rodriguez, G.; Trujillo, M.; Fernandez-Bolanos, J.; Espartero, J.L. Synthesis of hydroxytyrosyl alkyl ethers from olive oil waste waters. Molecules 2009, 14, 1762-1772, doi:10.3390/molecules14051762.

23. Trujillo, M.; Gallardo, E.; Madrona, A.; Bravo, L.; Sarria, B.; Gonzalez-Correa, J.A.; Mateos, R.; Espartero, J.L. Synthesis and antioxidant activity of nitrohydroxytyrosol and its acyl derivatives. J. Agric. Food Chem. 2014, 62, 10297-10303, doi:10.1021/jf503543x.

24. Trujillo, M.; Mateos, R.; Collantes de Teran, L.; Espartero, J.L.; Cert, R.; Jover, M.; Alcudia, F.; Bautista, J.; Cert, A.; Parrado, J. Lipophilic hydroxytyrosyl esters. Antioxidant activity in lipid matrices and biological systems. J. Agric. Food Chem. 2006, 54, 3779-3785, doi:10.1021/jf060520z. 
The 1st International Electronic Conference on Antioxidants in Health and Disease, 1-15 December 2020

25. Hormaechea-Agulla, D.; Gahete, M.D.; Jiménez-Vacas, J.M.; Gómez-Gómez, E.; Ibáñez-Costa, A.; Fernando, L.; Rivero-Cortés, E.; Sarmento-Cabral, A.; Valero-Rosa, J.; Carrasco-Valiente, J.; et al. The oncogenic role of the In1-ghrelin splicing variant in prostate cancer aggressiveness. Mol. Cancer 2017, 16, 146, doi:10.1186/s12943-017-0713-9.

26. Jimenez-Vacas, J.M.; Herrero-Aguayo, V.; Gomez-Gomez, E.; Leon-Gonzalez, A.J.; Saez-Martinez, P.; Alors-Perez, E.; Fuentes-Fayos, A.C.; Martinez-Lopez, A.; Sanchez-Sanchez, R.; Gonzalez-Serrano, T.; et al. Spliceosome component SF3B1 as novel prognostic biomarker and therapeutic target for prostate cancer. Transl. Res. 2019, 212, 89-103, doi:10.1016/j.trsl.2019.07.001.

27. Gomez-Gomez, E.; Jimenez-Vacas, J.M.; Pedraza-Arevalo, S.; Lopez-Lopez, F.; Herrero-Aguayo, V.; Hormaechea-Agulla, D.; Valero-Rosa, J.; Ibanez-Costa, A.; Leon-Gonzalez, A.J.; Sanchez-Sanchez, R.; et al. Oncogenic Role of Secreted Engrailed Homeobox 2 (EN2) in Prostate Cancer. J. Clin. Med. 2019, 8, 1400, doi:10.3390/jcm8091400.

28. Hormaechea-Agulla, D.; Jiménez-Vacas, J.M.; Gómez-Gómez, E.; López, F.L.; Carrasco-Valiente, J.; ValeroRosa, J.; Moreno, M.M.; Sánchez-Sánchez, R.; Ortega-Salas, R.; Gracia-Navarro, F.; et al.. The oncogenic role of the spliced somatostatin receptor sst5TMD4 variant in prostate cancer. FASEB J. 2017, 31, 4682-4696, doi:10.1096/fj.201601264RRR.

29. Jimenez-Vacas, J.M.; Herrero-Aguayo, V.; Montero-Hidalgo, A.J.; Gomez-Gomez, E.; Fuentes-Fayos, A.C.; Leon-Gonzalez, A.J.; Saez-Martinez, P.; Alors-Perez, E.; Pedraza-Arevalo, S.; Gonzalez-Serrano, T.; et al. Dysregulation of the splicing machinery is directly associated to aggressiveness of prostate cancer. EBioMedicine 2020, 51, 102547, doi:10.1016/j.ebiom.2019.11.008.

30. Del Rio-Moreno, M.; Alors-Perez, E.; Borges de Souza, P.; Prados-Gonzalez, M.E.; CastaNo, J.P.; Luque, R.M.; Gahete, M.D. Peptides derived from the extracellular domain of the somatostatin receptor splicing variant SST5TMD4 increase malignancy in multiple cancer cell types. Transl. Res. 2019, 211, 147-160, doi:10.1016/j.trsl.2019.02.013.

Publisher's Note: MDPI stays neutral with regard to jurisdictional claims in published maps and institutional affiliations.

(C) 2020 by the authors. Submitted for possible open access publication under the terms and conditions of the Creative Commons Attribution (CC BY) license (http://creativecommons.org/licenses/by/4.0/). 